\title{
Static vs. Time-Varying Beta of Fama-French Five Factors Model in Indonesia and Thailand
}

\author{
Atika* \\ Department of Management, Faculty of Economics and Business, Universitas Binawan \\ e-mail: atika@binawan.ac.id \\ Sigit Sulistyo Wibowo \\ Department of Management, Faculty of Economics and Business, Universitas Indonesia \\ e-mail: sigit.sw@ui.ac.id
}

\begin{abstract}
This paper empirically investigates the various approaches to model time-varying systematic risk in Indonesia and Thailand using time-series data from 2009 to 2017. Indonesia and Thailand were used as examples because of their growing economics since the turn of the 20th century. As recent empirical studies have been conducted on stock markets in developed countries, there is an increasing need for testing in emerging markets, which have grown and become increasingly popular with international investors, such as Indonesia and Thailand. This study examines dynamic beta models using GARCH $(1,1)$, EGARCH, TARCH, Schwert-Seguin, and the Kalman-Filter group to empirically find the most optimal time-varying beta model. This study uses the Fama-French Five Factors asset pricing model to include other factors that might influences value of systematic risk for each portfolio in both countries. This model can capture five factors that can affect returns, namely market factors (CAPM), size, book to market equity, profitability, and investment. By incorporating volatility and state space estimation, this study compares all tested models based on information criteria (AIC, SIC, and HIC). The results of this research proves that GARCH $(1,1)$ in Indonesia and TARCH in Thailand outperforms other models in capturing the systematic risk. This study will be useful for future economic studies in Indonesia, Thailand and their neighboring countries.
\end{abstract}

Keywords: EGARCH, Fama-French five factors, GARCH $(1,1)$, Kalman Filter, Schwert and Seguin, TARCH, Timevarying beta. 


\section{INTRODUCTION}

Stock markets exhibit volatility in returns from time to time. Theoretically, the changes in volatility lead to change in the rate of return demanded by investors and therefore resulting in the changes in stock price. The stock market volatility is influenced by the information available in the market. Because the arrival of information is dynamic, so the variance and co-variance of rate of return are also time-varying. The standard capital asset pricing model (CAPM) assumes that all investors have the homogenous expectations available information about the markets which assuming that beta is constant over a long period. Furthermore, standard models including CAPM or other static models constant volatility over time. However, due to the dependence of the systematic risk of an asset return on micro and macro factors, there is considerable empirical evidence documenting time variation in market betas. Beta indicates whether the investment is more or less volatile than the market as a whole. Beta is a measure of the risk arising from exposure to general market movements as opposed to idiosyncratic factors. It is important because it measures the risk of an investment that cannot be reduced by diversification (Sharpe, 1970).

Time varying beta is important to predict because it shows whether an investment is more or less stable than the market as a whole. Beta is a measure of risk arising from market movements in general which is not an idiosyncratic factor so that it cannot be reduced by diversification (Sharpe, 1970). Since beta (systematic risk) is a risk that investors should be concerned about, predicting beta values helps investors to make their investment decisions easier. For corporate financial managers, the conditional beta estimate not only benefits them in capital structure decisions, but also in investment appraisal.

As indicated by Brooks et al. (1998), several different econometric methods have been applied to test the time varying beta of various countries and companies. In this paper, we define time-varying beta of systematic risk based on beta in conditional variance. We use the symmetric model GARCH because it applies the information on the conditional variance to create a serial conditional beta. We also use the extensions of ARCH/GARCH model, called asymmetric model EGARCH and TARCH to accommodate impact of good news and bad news caused by leverage effect. Other than that, we also involve dynamic model of Kalman Filter which using temporal series of observable variables to reconstitute the value of the non-observable variables. The model is expressed on a state-space form. The Schwert and Seguin models are also used to capture various levels of volatility in the market index return by adding additional independent variables to equate the inverse of the market conditional volatility return.

The time variation of beta has been successfully applied in some literatures. Petkova and Zhang (2005); and Jagannathan and Wang (1996) found that beta is likely to vary over the business cycle. More over Nieto et al. (2014) and Faff et al. (2000) compares the performance of time-varying beta taken from different methodologies using CAPM model. While this approach has been widely used in the study of time-varying beta, Fama French Five Factor model has not, to the best of our knowledge, been applied as we propose.

Fama and French (1997); Ferson and Harvey (1999); and Campbell and Vuolteenaho (2004) show that time-varying beta helps to explain some anomalies such as size, industry and value. However, this conditional time-varying framework is not enough to improve the weakness of CAPM. The problem in dynamics beta is that the investor information is unobservable, so some assumptions needed to be made, such as assumptions of the dynamics betas and the conditional variance of returns. The dynamics betas could be estimated by Kalman Filter because it assumes standard stochastic processes such as random walk, autoregressive, mean reverting and switching models driving those dynamics. Another model used is Schwert and Seguin (1990). Then, the assumptions about the conditional variance return depend on the parametric approach of the ARCH / GARCH model, namely GARCH, EGARCH, and TARCH.s

As recent empirical studies have been conducted on stock markets in developed countries, there is an increasing need for testing in emerging markets, which have grown and become increasingly popular with international investors, such as Indonesia and Thailand. The two countries are the two countries with the largest GDP in ASEAN (IMF, 2019). In general, stock 
price movements are supported by the macroeconomic conditions of a country. Economic growth will affect the prospects for business growth in a country and this situation is quite encouraging share prices. The existence of business developments also provides the potential for increased profits that can be distributed as dividends to shareholders. One of the characteristics of investors is to hunt for stocks with good prospects so that the index moves up.

\section{Econometric Framework}

1. The Static Beta Using Fama French Five Factors

From the many asset pricing models, the Fama-French five-factor model (1992, 1993, 2015a) is chosen because it can accommodate the contribution of more factors to stock or portfolio returns. Here is the conditional mean equation of the Fama-French five-factor model:

$R_{p t}-R_{f t}=\alpha_{p}+\beta_{p}\left(R_{M t}-R_{f t}\right)+s_{p} S M B_{t}+h_{p} H M L_{t}+r_{p} R M W_{t}+c_{p} C M A_{t}+\varepsilon_{p t}$ $\mathrm{R}_{\mathrm{pt}}$ is portfolio stock return; $\mathrm{R}_{\mathrm{ft}}$ is risk-free rate; $\mathrm{R}_{\mathrm{Mt}}$ is market return; $\mathrm{SMB}_{\mathrm{t}}$ is size factor (small minus big); $\mathrm{HML}_{\mathrm{t}}$ is value factor (high minus Low); $\mathrm{RMW}_{\mathrm{t}}$ is profitability factor (robust minus weak); $\mathrm{CMA}_{\mathrm{t}}$ is investment factor (conservative minus aggressive); $\varepsilon_{\mathrm{pt}}$ is error term. Regression of this equation is using Ordinary Least Square to get the static beta.

2. The Time Varying Beta

2.1. The Symmetric GARCH $(1,1)$

The Generalized Autoregressive Conditional Heteroscedasticity (GARCH) model, which was also built by Bollerslev (1986), states that conditional variance depends on the size of itself and squared residuals in the previous period, so that the simplest GARCH $(1,1)$ equation becomes: $\sigma_{1}^{2}=\alpha+\gamma_{i} \varepsilon_{t-1}^{2}+\beta_{i} \sigma_{t-1}^{2}$

The GARCH model states the estimated magnitude of variance, $\sigma_{t}^{2}$, is a function of a longterm average (indicated by constants, $\alpha$ ), new information about the volatility that occurred in the previous period (measured by the lag of the squared residuals obtained from the mean equation $\left(\varepsilon_{t-1}^{2}\right)$, which is called the ARCH terms and the magnitude of the expected variance of the previous period $\left(\sigma_{t}^{2}\right)$, which is called the GARCH terms. If the return on assets unexpectedly increases (or decreases) large enough, it can be seen from the residual squares that increase (or decrease) significantly, then it can be expected that the variance in the next period will increase.

If the mean equation (expected return model) produces a small square error, it means that the prediction of the model against the realization data is quite good, then the variance of return (volatility) in the next period will be small. This is consistent with the phenomenon of volatility clustering that we often encounter in financial asset return data when large changes in yields will tend to be followed by even greater changes, until a period where the effects of shocks gradually disappear so that a period of high volatility ends followed by a period with lower volatility.

2.2. The Exponential GARCH Model

Exponential-GARCH model formulated by Nelson (1991). The EGARCH model is as follows:

$\ln \left(\sigma_{p t}^{2}\right)=\omega+\alpha_{1}\left(\left|\frac{\varepsilon_{p t-1}}{\sigma_{p t-1}}\right|-\sqrt{\frac{2}{\pi}}\right)+\gamma \frac{\varepsilon_{p t-1}}{\sigma_{p t-1}}+\beta_{1} \ln \left(\sigma_{p t-1}^{2}\right)$

The left side of Nelson's model is the conditional variance log that shows the exponential leverage effect, not quadratic, and conditional variance forecast can be ascertained non-negative. The leverage effects can be seen from the significance of $\gamma$ if significantly different from zero, $\gamma \neq 0$, and marked positive then it can be said volatility is asymmetric. If $\gamma$ is not significantly different from zero, $\gamma=0$, then basically the volatility model we get is a GARCH model, a symmetric volatility model. The arrival of shocks that have a negative impact on asset values causes prices to decline and firms' debt to equity levels to increase. On the other hand, positive shocks increase prices causing a decrease in this leverage effect. The value of $\alpha$ parameter

Jurnal Manajeme dan Organisasi

(JMO),

Vol. 11 No. 3, Hal. 189-202
$(\mathrm{ARCH})$ is interpreted as a measure of (past) innovation effect on volatility (small $\alpha$ means small impact of innovation), while $\beta$ (GARCH) as an impact of past value of volatility on today's volatility. 


\subsection{The Threshold ARCH Model}

Model from Glosten, Jagannathan, dan Runkle (1993) (hereafter GJR) is similar to EGARCH specification with conditional variance equation as follows:

$\sigma_{p t}^{2}=\omega+\alpha_{1} \varepsilon_{p t-1}^{2}+\gamma I_{t-1} \varepsilon_{p t-1}^{2}+\beta_{1} \sigma_{p t-1}^{2}$

TARCH specification attempts to model the asymmetry in the stock price volatility reaction to information shocks by utilizing dummy variables to differentiate between positive and negative shocks. Bad news (decrease in return) has larger effect to conditional variance where dummy variable is $1, \mathrm{I}_{\mathrm{t}-1}=1$, whereas effect of good news (increase in return) is not as large as bad news. In the equation, $\beta$ denotes GARCH parameter and $\alpha$ denotes $\mathrm{ARCH}$ parameter.

2.4. Schwert and Seguin

The Schwert and Seguin time varying beta model (1990) add a model that could capture the level of volatility that exists in market returns. This approach can be seen in the framework of a commonly used market model, where the beta is time varying. Specifically, the authors obtain the Schwert and Seguin beta specifications by choosing additional independent variables to equal the inverse conditional volatility of the market yield series. With the time-varying beta method from Schwert Seguin, the authors continue to use the five-factor Fama French asset pricing model as below:

$$
\begin{aligned}
R_{p t}-R_{f t}=\alpha_{p} & +\beta_{1}\left(R_{M t}+\beta_{2}\left(\frac{R_{M t}-R_{f t}}{\sigma_{M t}^{2}}\right)\right)+s_{p} S M B_{t}+h_{p} H M L_{t}+r_{p} R M W_{t}+c_{p} C M A_{t} \\
& +\varepsilon_{i}
\end{aligned}
$$

This approach adds a constant mean with time varying beta. Following Schwert and Seguin (1990), conditional variance of market used in this study was obtained from the GARCH process $(1,1)$ and paired with a series of market returns.

2.5. The Kalman Filter Model

A dynamic system such as the time-varying risk return process that has been proposed in this paper can be represented in a general form known as the state space model. In this form we define an observation (or measurement) equation and a transition (or state) equation, which together describe the structure and dynamics of a system. A state space form allows us to incorporate unobserved variables into, and estimate them along with, the observable model to impose a time varying structure to beta. State space models are estimated using a powerful recursive algorithm known as the Kalman Filter. In a paper from Budapest Econometric Society 1972, Schaefer et al. (1975) considered four different beta models, they are OLS model, random coefficient model (RCF), random walk model (RW), and mean reverting model (MRV) (Wells, 1996).

- Random coefficient model : $\beta_{p t}^{R C F}=\bar{\beta}+\mu_{p t-1}$

The coefficient fluctuates randomly around the mean.

- Random walk model : $\beta_{p t}^{R W}=\beta_{p t-1}+v_{p t-1}$

In this model the coefficient moves randomly. In Wells (1996) mentioned that Schaefer et al. cite two previous studies of beta which have used this model as a starting point, namely the Office in the Journal of Financial Analysis in 1971 and Fisher \& Kamin in a paper presented in 1971 in Chicago.

- Mean reverting model: $\beta_{p t}^{M R V}=\emptyset \beta_{p t-1}+(1-\emptyset) \bar{\beta}+\zeta_{p t-1}$

This model is also called AR (1), where beta moves gradually toward its mean. All four models (including OLS) can be considered as special cases of MRV: OLS model is obtained when var $\left(\zeta_{\mathrm{pt}-1}\right)=0$, RCF when $\phi=0$, and RW when $\phi=1$.

Coefficient of $\mu_{\mathrm{pt}-1}, \mathrm{v}_{\mathrm{pt}-1}$, and $\zeta_{\mathrm{pt}-1}$ are random variables that follows the Gaussian distribution with zero mean and fixed variance, that is, the coefficient tends to return to its mean. In Wells (1996) mentioned that Schaefer et al. presents a method for distinguishing between the four models and concludes that beta is unstable and is best explained by the MRV model over a 45- 
year period (1926-1971) using monthly returns. However, the benefit in their paper is the introduction of various models for beta rather than the test methodology used.

\section{METHODOLOGY}

We use daily returns data of Indonesia (IDX) and Thailand (SETI) from 1 January 2009 to 31 December 2017. The data is obtained from Datastream. Portfolio of this research is formed based on Fama-French five factors, there are size-value, size-profitability, and size-investment that generates 18 value-weighted portfolios (consisting of 6 portfolios size-value, 6 portfolios size-profitability, and 6 portfolios size-investment). Size divided into small, and big, and another factor divided into low, medium and high. According to Fama and French (1992), we exclude the financial institutions in this research. We use market capitalization as proxy for size, book to market as value, operating profit margin as profitability, and asset growth as investment factor.

The dependent variable in this study is the return of each portfolio, while the independent variable is the asset pricing factor, which consists of market factor, size factor, value factor, profitability factor, and investment factor. Calculation of asset pricing factor using $2 \times 3$ portfolio sorting. The calculation result of factors below will be used in equation of the Fama-French fivefactor model:

- Market Factor (Rm - Rf)

Market factor is the daily difference between market returns and risk-free rate.

- Size Factor (SMB)

SMB (Small Minus Big) is daily difference between average return of nine small stock portfolios with average return of nine big stock portfolios.

$$
\begin{aligned}
& \operatorname{SMB}_{\left(\frac{B}{M}\right)}=\frac{(\text { Small Value }+ \text { Small Neutral }+ \text { Small Growth })}{3} \\
& S M B_{(O P)}=\frac{(\text { Sig Value }+ \text { Big Neutral }+ \text { Big Growth })}{3} \\
& -\frac{(\text { Big Robust }+ \text { Big Neutral }+ \text { Big Weak })}{3} \\
& S M B_{(I N V)}=\frac{(\text { Small Conservative }+ \text { Small Neutral }+ \text { Small Aggressive })}{3} \\
& -\frac{(\text { Big Conservative }+ \text { Big Neutral }+ \text { Big Aggressive })}{3}
\end{aligned}
$$

- Value Factor (HML)

HML (High Minus Low) is daily difference between average return of two portfolios with high and low book-to-market ratio.

$$
H M L=\frac{(\text { Small Value }+ \text { Big Value })}{2}-\frac{(\text { Small Growth }+ \text { Big Growth })}{2}
$$

- Profitability Factor (RMW)

RMW (Robust Minus Weak) is daily difference between average return of two portfolios with high and small operating profitability.

- Investment Factor (CMA)

$$
R M W=\frac{(\text { Small Robust }+ \text { Big Robust })}{2}-\frac{(\text { Small Weak }+ \text { Big Weak })}{2}
$$

CMA (Conservative Minus Aggressive) is daily difference between average return of two portfolios with conservative (low) investment and aggressive (high) investment. 


$$
\begin{aligned}
& \text { CMA }=\frac{(\text { Small Conservative }+ \text { Big Conservative })}{2} \\
& -\frac{(\text { Small Aggressive }+ \text { Big Aggressive })}{2}
\end{aligned}
$$

Fama and French (2015) found that the five-factor model is better than the three-factor model in explaining stock excess return in the United States. This reason makes the author to obtain time varying beta on market risk using the Fama-French five factors model. The portfolio formed from this model also provides a systematic risk effect that varies with time for each portfolio.

\section{The Optimal Model Testing}

The data we used has passed the prerequisite test of stationary, multicolinearity, heteroskedasticity, and autocorrelation. Inspired by Faff et al. (2000), our analysis consists of three parts. First is obtaining static beta, second part is modelling conditional beta series (timevarying), then the last stage is determining of the optimal model from characterising the conditional beta series for all portfolios using the three most popular information criterion, they are Akaike Information Criterion (AIC), Schwarz-Bayesian Information Criterion (SIC), and Hannan-Quinn Information Criterion (HIC) as below:

$$
\begin{aligned}
& A I C=\ln \left(\hat{\sigma}^{2}\right)+\frac{2 k}{T} \\
& S I C=\ln \left(\hat{\sigma}^{2}\right)+\frac{k}{T} \ln T \\
& H I C=\ln \left(\hat{\sigma}^{2}\right)+\frac{2 k}{T} \ln (\ln T)
\end{aligned}
$$

With

$\hat{\sigma}^{2}$ : Residual of variance (equivalent to residual sum of squares divided by number of observations)

$k \quad$ : Number of parameters estimated in the regression model (including intercept)

$T$ : Number of observations

The advantage of AIC is it has an advantage of goodness of fit (as calculated by the likelihood function) and includes a penalty which is a function of increasing the estimated number of parameters. Penalties prevent over fitting because increasing the number of parameters in a model almost always increases the goodness of fit. The meaning of the goodness of fit of a statistical model illustrates how well the model matches the set of observations tested.

When a statistical model is used to represent the process that produces data, the model almost never be exact so that some information will be lost by using a model to represent the process. AIC estimates the information that is relatively lost by the given model: the less information lost by the model, the higher the quality of the model. However, in estimating missing information, AIC faces a trade-off between the goodness of fit of modelling and the simplicity of the model. Brooks (2014) adds that SIC is closely related to AIC but SIC adds a tighter penalty than AIC, while HIC is between the two.

\section{RESULTS AND DISCUSSION}

\section{Descriptive Statistics in Indonesia}

Statistical descriptions for each of the independent variables for daily data for the period January 2009 to December 2017 (2346 observations) in Indonesia can be seen in Table 1 Panel A. The independent variables used are 5 fact

or variables that affect portfolio returns, namely market factors, size, value, profitability, and investment. Through a filtering process carried out with a purposive sampling method, from a total of 582 companies listed on the Indonesia Stock Exchange, 411 companies were taken to exclude financial companies, companies with negative book to market ratios and companies with inappropriate or unavailable data. 
Table 1. The Statistics Summary of Asset Pricing Factors and Correlation - Indonesia

\begin{tabular}{|c|c|c|c|c|c|}
\hline \multicolumn{6}{|c|}{ Panel A: The Statistics Summary of Asset Pricing Factors } \\
\hline & $R m-R f$ & $S M B$ & $H M L$ & $R M W$ & $C M A$ \\
\hline Mean & 0,00046 & 0,00105 & 0,00693 & $-0,00062$ & $-0,00023$ \\
\hline Median & 0,00023 & 0,00000 & 0,00462 & 0,00000 & 0,00000 \\
\hline Maximum & 0,07240 & 0,04925 & 0,20167 & 0,02293 & 0,04400 \\
\hline Minimum & $-0,08906$ & $-0,04581$ & $-0,23828$ & $-0,03471$ & $-0,04687$ \\
\hline Std. Dev. & 0,01105 & 0,00920 & 0,03755 & 0,00625 & 0,00546 \\
\hline \multicolumn{6}{|c|}{ Panel B: Correlations } \\
\hline & $R m-R f$ & $S M B$ & $H M L$ & $R M W$ & $C M A$ \\
\hline$R m-R f$ & 1,00000 & $-0,22580$ & 0,39441 & 0,21112 & 0,15157 \\
\hline$S M B$ & & 1,00000 & 0,64989 & $-0,18783$ & $-0,02652$ \\
\hline$H M L$ & & & 1,00000 & $-0,06841$ & 0,08329 \\
\hline$R M W$ & & & & 1,00000 & $-0,16023$ \\
\hline$C M A$ & & & & & 1,00000 \\
\hline
\end{tabular}

The correlation between the independent variables must be seen to determine the direction of the relationship between variables. Table 1 Panel B presents the correlation between the independent variables. The size factor (SMB) has a negative correlation with market factors (RmRf), while other factors, namely value (HML), profitability (RMW), and investment (CMA) have a positive correlation with market factors. The SMB factor correlates positively with HML and negatively correlates with RMW and CMA. HML factor negatively correlates with RMW and positively correlates with CMA. The RMW factor has a negative correlation with CMA. Table 2 presents the characteristics of the 18 portfolios that are formed based on 6 Size-B/M, 6 size-OP, dan 6 size-INV. The table presents the various number of shares and yield average for each small and big companies based on B/M, profitability, and investments in Panel A and B. Panel C proves that market capitalization for small category company is less than big category company. Panel $\mathrm{D}, \mathrm{E}$, and $\mathrm{F}$ represents the percentage of $\mathrm{B} / \mathrm{M}$, profitability, and investments for each portfolio.

Table 2. Portfolio Characteristics Size - B/M, Size - OP, and Size-Inv Indonesia

\begin{tabular}{|c|c|c|c|c|c|c|c|c|c|}
\hline & \multicolumn{3}{|c|}{ Book to Market (HML) } & \multicolumn{3}{|c|}{ Profitability (RMW) } & \multicolumn{3}{|c|}{ Investments (CMA) } \\
\hline & Low & Med & High & Low & Med & High & Low & Med & High \\
\hline \multicolumn{10}{|c|}{ Panel A : The Number of Shares per Portfolio } \\
\hline Small & 51,00 & 70,00 & 84,00 & 79,00 & 82,00 & 44,00 & 81,00 & 67,00 & 57,00 \\
\hline Big & 72,00 & 95,00 & 39,00 & 44,00 & 83,00 & 79,00 & 42,00 & 98,00 & 66,00 \\
\hline \multicolumn{10}{|c|}{ Panel B : Yield Average (In Percentage) } \\
\hline Small & 0,05 & 0,12 & 1,41 & 0,15 & 0,07 & 0,07 & 0,06 & 0,11 & 0,09 \\
\hline Big & 0,13 & 0,12 & 0,15 & 0,15 & 0,14 & 0,11 & 0,12 & 0,12 & 0,14 \\
\hline \multicolumn{10}{|c|}{ Panel C : Market Capitalization (In Percentage) } \\
\hline Small & 0,26 & 0,73 & 0,84 & 0,73 & 0,82 & 0,27 & 0,88 & 0,72 & 0,22 \\
\hline Big & 71,68 & 21,65 & 4,84 & 6,30 & 34,44 & 57,43 & 20,95 & 64,74 & 12,48 \\
\hline \multicolumn{10}{|c|}{ Panel D : Book to Market (In Percentage) } \\
\hline Small & 3,41 & 13,18 & 42,52 & 25,64 & 23,95 & 9,53 & 30,27 & 18,56 & 10,29 \\
\hline Big & 5,10 & 16,51 & 19,27 & 11,18 & 17,67 & 12,03 & 10,27 & 16,18 & 14,43 \\
\hline \multicolumn{10}{|c|}{ Panel E : Profitability (In Percentage) } \\
\hline Small & 12,44 & 16,95 & 20,48 & 19,02 & 20,04 & 10,81 & 19,70 & 16,36 & 13,81 \\
\hline Big & 17,63 & 23,22 & 9,28 & 10,41 & 20,30 & 19,42 & 10,27 & 24,01 & 15,85 \\
\hline \multicolumn{10}{|c|}{ Panel F : Investments (In Percentage) } \\
\hline Small & 60,32 & 1,51 & 6,10 & 3,02 & 6,24 & 58,67 & 0,23 & 0,81 & 66,89 \\
\hline Big & 5,34 & 6,91 & 19,82 & 23,88 & 6,76 & 1,43 & 0,18 & 1,21 & 30,67 \\
\hline
\end{tabular}

\section{Empirical Result in Indonesia}

This test compares beta as a measure of volatility or systematic risk of the portfolio against

Jurnal Manajemen dan Organisasi

(Jol.

Vol. 11 No. 3, Hal. 189-202 the market as a whole. The author uses three information criteria, namely AIC, SIC, and HIC to determine the optimal conditional beta modeling. The best model criteria is the one with the smallest information criteria value. Based on Fama French's five-factor model, the authors use 
nine models to form time-varying beta for each 6 Size-B/M, 6 Size-OP, and 6 Size-INV portfolios, as follows:

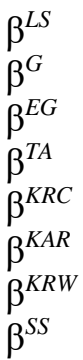

$$
\begin{aligned}
& =\text { Ordinary least square atau beta statis } \\
& =\text { GARCH }(1,1) \\
& =\text { EGARCH } \\
& =\text { TARCH } \\
& =\text { Kalman Filter Random Coefficient } \\
& =\text { Kalman Filter AR }(1) / \text { Mean Reverting } \\
& =\text { Kalman Filter Random Walk } \\
& =\text { Schwert dan Seguin GARCH }
\end{aligned}
$$

\begin{tabular}{|c|c|c|c|c|c|c|c|c|c|c|c|c|c|c|c|}
\hline Portfolio & $\beta^{L}$ & & $A I C$ & SIC & $H I C$ & $\beta^{C}$ & & $A I C$ & SIC & HIC & $\beta^{E C}$ & & $A I C$ & SIC & HIC \\
\hline $\mathrm{S} / \mathrm{L} \mathrm{BM}$ & 0,156 & $* * *$ & $-8,985$ & $-8,971$ & $-8,980$ & 0,013 & $* * *$ & $-11,580$ & $-11,560$ & $-11,570$ & 0,014 & $* * *$ & $-11,570$ & $-11,550$ & 11,560 \\
\hline S/M BM & 0,322 & $* * *$ & $-7,495$ & $-7,480$ & $-7,490$ & 0,298 & $* * *$ & $-7,538$ & $-7,516$ & $-7,530$ & 0,301 & $* * *$ & $-7,533$ & $-7,509$ & $-7,524$ \\
\hline S/H BM & 0,737 & $* * *$ & $-6,738$ & $-6,723$ & $-6,732$ & 0,742 & $* * *$ & $-6,758$ & $-6,736$ & $-6,750$ & 0,737 & $* * *$ & $-6,759$ & $-6,735$ & $-6,750$ \\
\hline $\begin{array}{l}\mathrm{B} / \mathrm{L} \mathrm{BM} \\
\mathrm{B} / \mathrm{M}\end{array}$ & 0,462 & $* * *$ & $-8,354$ & $-8,339$ & $-8,348$ & 0,467 & $* * *$ & $-8,394$ & $-8,372$ & $-8,386$ & 0,470 & $* * *$ & $-8,389$ & $-8,365$ & $-8,380$ \\
\hline $\mathrm{BM}$ & 0,335 & $* * *$ & $-8,190$ & $-8,175$ & $-8,184$ & $\begin{array}{r}0,305 \\
-\end{array}$ & $* * *$ & $-8,237$ & $-8,209$ & $-8,225$ & 0,303 & $* * *$ & $-8,234$ & $-8,215$ & $-8,229$ \\
\hline B/H BM & $-0,119$ & $* * *$ & $-7,135$ & $-7,120$ & $-7,130$ & 0,252 & $* * *$ & $-7,290$ & $-7,268$ & $-7,282$ & $-0,251$ & $* * *$ & $-7,289$ & $-7,265$ & $-7,280$ \\
\hline S/L OP & 0,365 & $* * *$ & $-7,770$ & $-7,755$ & $-7,765$ & 0,242 & $* * *$ & $-8,108$ & $-8,086$ & $-8,100$ & 0,239 & $* * *$ & $-8,099$ & $-8,074$ & $-8,090$ \\
\hline S/M OP & 0,194 & $* * *$ & $-8,419$ & $-8,405$ & $-8,414$ & 0,060 & $* * *$ & $-10,150$ & $-10,130$ & $-10,140$ & 0,064 & $* * *$ & $-10,150$ & $-10,120$ & 10,140 \\
\hline S/H OP & 0,022 & $* *$ & $-8,533$ & $-8,518$ & $-8,527$ & 0,002 & & $-8,744$ & $-8,722$ & $-8,736$ & $-0,004$ & & $-8,743$ & $-8,719$ & $-8,734$ \\
\hline $\mathrm{B} / \mathrm{L}$ OP & 0,049 & $* * *$ & $-7,760$ & $-7,746$ & $-7,755$ & 0,035 & $* * *$ & $-7,910$ & $-7,888$ & $-7,902$ & 0,042 & $* * *$ & $-7,908$ & $-7,884$ & $-7,899$ \\
\hline $\mathrm{B} / \mathrm{M}$ OP & 0,404 & $* * *$ & $-8,175$ & $-8,160$ & $-8,169$ & 0,372 & $* * *$ & $-8,222$ & $-8,200$ & $-8,214$ & 0,373 & $* * *$ & $-8,213$ & $-8,189$ & $-8,204$ \\
\hline B/H OP & 0,392 & $* * *$ & $-8,508$ & $-8,493$ & $-8,502$ & 0,343 & $* * *$ & $-8,595$ & $-8,573$ & $-8,587$ & 0,343 & $* * *$ & $-8,590$ & $-8,566$ & $-8,581$ \\
\hline $\begin{array}{l}\text { S/L INV } \\
\text { S/M }\end{array}$ & 0,152 & $* * *$ & $-8,318$ & $-8,303$ & $-8,312$ & 0,050 & $* * *$ & $-9,696$ & $-9,674$ & $-9,688$ & 0,051 & $* * *$ & $-9,726$ & $-9,701$ & $-9,717$ \\
\hline INV & 0,252 & $* * *$ & $-8,054$ & $-8,039$ & $-8,049$ & 0,161 & $* * *$ & $-8,490$ & $-8,467$ & $-8,482$ & 0,165 & $* * *$ & $-8,473$ & $-8,449$ & $-8,464$ \\
\hline S/H INV & 0,196 & $* * *$ & $-8,087$ & $-8,072$ & $-8,082$ & 0,027 & $* * *$ & $-9,902$ & $-9,880$ & $-9,894$ & 0,026 & $* * *$ & $-9,897$ & $-9,872$ & $-9,888$ \\
\hline $\begin{array}{l}\text { B/L INV } \\
\mathrm{B} / \mathrm{M}\end{array}$ & 0,222 & $* * *$ & $-8,097$ & $-8,082$ & $-8,091$ & 0,117 & $* * *$ & $-8,495$ & $-8,473$ & $-8,487$ & 0,120 & $* * *$ & $-8,486$ & $-8,461$ & $-8,477$ \\
\hline $\begin{array}{l}\text { INV } \\
\text { B/H }\end{array}$ & 0,470 & $* * *$ & $-8,614$ & $-8,600$ & $-8,609$ & 0,465 & $* * *$ & $-8,664$ & $-8,642$ & $-8,656$ & 0,468 & $* * *$ & $-8,660$ & $-8,636$ & $-8,652$ \\
\hline INV & 0,178 & $* * *$ & $-8,101$ & $-8,087$ & $-8,096$ & 0,126 & $* * *$ & $-8,450$ & $-8,428$ & $-8,442$ & 0,130 & $* * *$ & $-8,438$ & $-8,413$ & $-8,429$ \\
\hline
\end{tabular}

\begin{tabular}{|c|c|c|c|c|c|c|c|c|c|c|c|c|c|}
\hline Portfolio & $\beta^{T}$ & & AIC & SIC & HIC & $\beta^{K R C}$ & AIC & $S I C$ & HIC & $\beta^{K A R}$ & $A I C$ & SIC & HIC \\
\hline S/L BM & 0,014 & **** & $-11,600$ & $-11,570$ & $-11,590$ & $-1,232$ & $-2,887$ & $-2,880$ & $-2,885$ & $-1,264$ & $-2,887$ & $-2,877$ & $-2,883$ \\
\hline S/M BM & 0,298 & **** & $-7,537$ & $-7,513$ & $-7,528$ & 2,936 & $-1,615$ & $-1,608$ & $-1,612$ & 2,938 & $-1,614$ & $-1,604$ & $-1,611$ \\
\hline S/H BM & 0,740 & **** & $-6,758$ & $-6,733$ & $-6,749$ & $-1,330$ & $-1,341$ & $-1,333$ & $-1,338$ & $-1,345$ & $-1,340$ & $-1,330$ & $-1,336$ \\
\hline $\mathrm{B} / \mathrm{L} \mathrm{BM}$ & 0,467 & **** & $-8,394$ & $-8,369$ & $-8,385$ & $-0,491$ & $-3,000$ & $-2,992$ & $-2,997$ & $-0,526$ & $-2,999$ & $-2,989$ & $-2,996$ \\
\hline $\mathrm{B} / \mathrm{M}$ BM & 0,303 & *** & $-8,237$ & $-8,213$ & $-8,228$ & 0,332 & $-4,176$ & $-4,168$ & $-4,173$ & 0,377 & $-4,177$ & $-4,167$ & $-4,174$ \\
\hline B/H BM & $-0,254$ & **** & $-7,295$ & $-7,271$ & $-7,286$ & $-0,393$ & $-2,361$ & $-2,354$ & $-2,358$ & $-0,417$ & $-2,360$ & $-2,350$ & $-2,357$ \\
\hline S/L OP & 0,241 & **** & $-8,110$ & $-8,086$ & $-8,101$ & 0,578 & $-3,158$ & $-3,151$ & $-3,155$ & 0,612 & $-3,157$ & $-3,148$ & $-3,154$ \\
\hline S/M OP & 0,060 & *** & $-10,160$ & $-10,140$ & $-10,150$ & $-1,040$ & $-2,883$ & $-2,876$ & $-2,880$ & $-1,046$ & $-2,882$ & $-2,872$ & $-2,879$ \\
\hline S/H OP & 0,002 & & $-8,745$ & $-8,721$ & $-8,736$ & $-0,201$ & $-3,475$ & $-3,468$ & $-3,473$ & $-0,067$ & $-3,475$ & $-3,465$ & $-3,471$ \\
\hline $\mathrm{B} / \mathrm{L}$ OP & 0,036 & **** & $-7,910$ & $-7,885$ & $-7,901$ & $-0,522$ & $-2,483$ & $-2,475$ & $-2,480$ & $-0,522$ & $-2,482$ & $-2,472$ & $-2,478$ \\
\hline B/M OP & 0,372 & **** & $-8,222$ & $-8,198$ & $-8,213$ & $-0,3$ & $-3,009$ & $-3,002$ & $-3,006$ & $-0,369$ & $-3,008$ & $-2,998$ & $-3,004$ \\
\hline B/H OP & 0,342 & *** & $-8,597$ & $-8,572$ & $-8,588$ & 0,256 & $-4,075$ & $-4,068$ & $-4,073$ & 0,236 & $-4,075$ & $-4,065$ & $-4,071$ \\
\hline S/L INV & 0,050 & *** & $-9,696$ & $-9,671$ & $-9,687$ & $-0,675$ & $-3,685$ & $-3,678$ & $-3,682$ & $-0,957$ & $-3,686$ & $-3,676$ & $-3,682$ \\
\hline S/M INV & 0,151 & *** & & $-8,471$ & $-8,486$ & & $-2,108$ & & $-2,105$ & 1,658 & $-2,108$ & $-2,098$ & $-2,104$ \\
\hline $\mathrm{S} / \mathrm{H}$ INV & 0,027 & $* * *$ & & $-9,877$ & $-9,892$ & $-2,8$ & $-1,202$ & & $-1,200$ & $-2,814$ & $-1,202$ & $-1,192$ & $-1,198$ \\
\hline $\mathrm{B} / \mathrm{L}$ INV & 0,119 & **** & $-8,496$ & $-8,471$ & $-8,487$ & $-1,653$ & $-1,927$ & $-1,920$ & $-1,924$ & $-1,651$ & $-1,926$ & $-1,916$ & $-1,922$ \\
\hline $\mathrm{B} / \mathrm{M}$ INV & 0,465 & *** & $-8,664$ & $-8,639$ & $-8,655$ & 0,156 & $-3,692$ & $-3,685$ & $-3,689$ & 0,149 & $-3,691$ & $-3,682$ & $-3,688$ \\
\hline B/H INV & 0,126 & **** & $-8,449$ & $-8,424$ & $-8,440$ & 0,516 & $-3,867$ & $-3,859$ & $-3,864$ & 0,671 & $-3,867$ & $-3,857$ & $-3,863$ \\
\hline
\end{tabular}

Table 3. The Comparison of Time-Varying Beta and Information Criteria - Indonesia 


\begin{tabular}{lrlllllll}
\hline Portfolio & \multicolumn{1}{c}{$\beta^{\text {KRW }}$} & \multicolumn{1}{l}{ AIC } & \multicolumn{1}{l}{ SIC } & \multicolumn{1}{l}{ HIC } & \multicolumn{1}{c}{ SS } & \multicolumn{1}{l}{ AIC } & \multicolumn{1}{l}{ SIC } & \multicolumn{1}{l}{ HIC } \\
\hline S/L BM & $-3,812$ & $-2,207$ & $-2,202$ & $-2,205$ & $0,17 \times 10^{-5} * *$ & $-8,986$ & $-8,969$ & $-8,980$ \\
S/M BM & 2,752 & $-0,913$ & $-0,908$ & $-0,911$ & $0,05 \times 10^{-5}$ & $-7,494$ & $-7,477$ & $-7,488$ \\
S/H BM & $-3,556$ & $-0,654$ & $-0,650$ & $-0,653$ & $1,33 \times 10^{-5} * * *$ & $-6,749$ & $-6,732$ & $-6,743$ \\
B/L BM & $-2,555$ & $-2,323$ & $-2,318$ & $-2,322$ & $0,75 \times 10^{-5} * * *$ & $-8,373$ & $-8,356$ & $-8,367$ \\
B/M BM & 1,197 & $-3,534$ & $-3,529$ & $-3,533$ & $0,05 \times 10^{-5}$ & $-8,189$ & $-8,172$ & $-8,183$ \\
B/H BM & $-2,811$ & $-1,677$ & $-1,672$ & $-1,675$ & $-0,41 \times 10^{-5} * *$ & $-7,136$ & $-7,119$ & $-7,130$ \\
S/L OP & 3,194 & $-2,478$ & $-2,473$ & $-2,476$ & $0,32 \times 10^{-5 * *}$ & $-7,771$ & $-7,754$ & $-7,765$ \\
S/M OP & $-6,900$ & $-2,191$ & $-2,186$ & $-2,189$ & $0,13 \times 10^{-5}$ & $-8,419$ & $-8,402$ & $-8,413$ \\
S/H OP & 5,449 & $-2,807$ & $-2,802$ & $-2,805$ & $0,18 \times 10^{-5} *$ & $-8,533$ & $-8,516$ & $-8,527$ \\
B/L OP & 0,343 & $-1,789$ & $-1,784$ & $-1,787$ & $0,42 \times 10^{-5} * * *$ & $-7,763$ & $-7,746$ & $-7,757$ \\
B/M OP & $-0,213$ & $-2,312$ & $-2,307$ & $-2,311$ & $-0,01 \times 10^{-5}$ & $-8,174$ & $-8,157$ & $-8,167$ \\
B/H OP & $-1,912$ & $-3,391$ & $-3,386$ & $-3,389$ & $0,56 \times 10^{-5} * * *$ & $-8,520$ & $-8,503$ & $-8,513$ \\
S/L INV & $-8,009$ & $-3,031$ & $-3,026$ & $-3,029$ & $0,29 \times 10^{-5} * * *$ & $-8,320$ & $-8,303$ & $-8,314$ \\
S/M INV & 2,369 & $-1,439$ & $-1,434$ & $-1,437$ & $0,15 \times 10^{-5}$ & $-8,054$ & $-8,037$ & $-8,048$ \\
S/H INV & 0,848 & $-0,517$ & $-0,512$ & $-0,515$ & $0,02 \times 10^{-5}$ & $-8,086$ & $-8,069$ & $-8,080$ \\
B/L INV & 3,938 & $-1,234$ & $-1,229$ & $-1,232$ & $0,45 \times 10^{-5} * * *$ & $-8,101$ & $-8,084$ & $-8,095$ \\
B/M INV & $-0,733$ & $-3,007$ & $-3,002$ & $-3,005$ & $0,04 \times 10^{-5}$ & $-8,614$ & $-8,596$ & $-8,607$ \\
B/H INV & $-4,918$ & $-3,146$ & $-3,141$ & $-3,144$ & $0,76 \times 10^{-5} * * *$ & $-8,117$ & $-8,100$ & $-8,110$ \\
\hline
\end{tabular}

Note: *** indicates a confidence level at 1 percent, ** indicates a confidence level at 5 percent, and $*$ indicates a confidence level at 10 percent.

Based on the comparison of information criteria for time-varying beta in Table 3, it shows that the most optimal modeling in Indonesia is the GARCH model $(1,1)$. However, the difference in optimization power between the GARCH $(1,1)$ and TARCH models is not too different, so the second most optimal model is TARCH. The GARCH model $(1,1)$ also yields a significant beta at the $1 \%$ level, except for the S/H OP portfolio. When compared with all other models, the highest value for the information criteria is the Kalman Filter model, which means that other models are more optimal than the Kalman Filter. This shows that the compatibility of the Kalman Filter model with existing data and the value that occurs in the future is lower than other models.

\section{Descriptive Statistics in Thailand}

Statistical descriptions for each of the independent variables for daily data from January 2009 to December 2017 (2346 observations) in Thailand can be seen in Table 4 Panel A. The independent variables used are 5 factor variables that affect portfolio returns, namely market factors, size, value, profitability, and investment.

Table 4. The Statistics Summary of Asset Pricing Factors and Correlation - Thailand

\begin{tabular}{|c|c|c|c|c|c|}
\hline \multicolumn{6}{|c|}{ Panel A: The Statistics Summary of Asset Pricing Factors } \\
\hline & $R m-R f$ & $S M B$ & $H M L$ & $R M W$ & $C M A$ \\
\hline Mean & $-0,00071$ & $-0,00231$ & 0,01117 & 0,00037 & $-0,00038$ \\
\hline Median & $-0,00036$ & $-0,00157$ & 0,00752 & 0,00000 & $-0,00003$ \\
\hline Maximum & 0,05632 & 0,11571 & 0,67735 & 0,03630 & 0,02301 \\
\hline Minimum & $-0,06393$ & $-0,13737$ & $-0,57555$ & $-0,01895$ & $-0,02036$ \\
\hline Std. Dev. & 0,01049 & 0,02101 & 0,10034 & 0,00442 & 0,00469 \\
\hline \multicolumn{6}{|c|}{ Panel B: Correlations } \\
\hline & $R m-R f$ & $S M B$ & $H M L$ & $R M W$ & $C M A$ \\
\hline$R m-R f$ & 1,00000 & 0,62648 & $-0,60736$ & $-0,28123$ & 0,13891 \\
\hline$S M B$ & & 1,00000 & $-0,98745$ & $-0,36694$ & 0,23861 \\
\hline$H M L$ & & & 1,00000 & 0,39053 & $-0,27851$ \\
\hline$R M W$ & & & & 1,00000 & $-0,31245$ \\
\hline$C M A$ & & & & & 1,00000 \\
\hline
\end{tabular}

Jurnal Manajemen dan Organisasi JMO),

Ool. 11 No. 3, Hal. 189-202
Through a filtering process carried out with a purposive sampling method, from a total of 577 companies registered in SETI, 476 companies were taken to exclude financial companies, companies with negative book to market ratios and companies with inappropriate or unavailable data. The daily average value of the excess return market (Rm-Rf) is - 0,071 persen. This negative value can be caused by the political crisis that occurred in Thailand in 2013-2014 which caused 
instability in the financial market in Thailand. Table 5 presents the characteristics of the 18 portfolios that are formed based on 6 Size-B/M, 6 size-OP, dan 6 size-INV.

Table 5. Portfolio Characteristics Size - B/M, Size - OP, and Size-Inv Thailand

\begin{tabular}{|c|c|c|c|c|c|c|c|c|c|}
\hline & \multicolumn{3}{|c|}{ Book to Market (HML) } & \multicolumn{3}{|c|}{ Profitability (RMW) } & \multicolumn{3}{|c|}{ Investments (CMA) } \\
\hline & Low & Med & High & Low & Med & High & Low & Med & High \\
\hline \multicolumn{10}{|c|}{ Panel A : The Number of Shares per Portfolio } \\
\hline Small & 38 & 81 & 118 & 112 & 74 & 51 & 107 & 77 & 53 \\
\hline Big & 121 & 76 & 41 & 47 & 83 & 108 & 51 & 81 & 106 \\
\hline \multicolumn{10}{|c|}{ Panel B : Yield Average (In Percentage) } \\
\hline Small & $-2,15$ & 0,10 & 0,08 & 0,09 & 0,10 & 0,14 & 0,08 & 0,10 & 0,15 \\
\hline Big & 0,08 & 0,09 & 0,09 & 0,06 & 0,10 & 0,09 & 0,07 & 0,10 & 0,08 \\
\hline \multicolumn{10}{|c|}{ Panel C : Market Capitalization (In Percentage) } \\
\hline Small & 0,96 & 1,59 & 1,92 & 1,85 & 1,44 & 1,19 & 1,83 & 1,48 & 1,16 \\
\hline Big & 52,44 & 36,19 & 6,89 & 12,31 & 40,22 & 43,00 & 16,50 & 39,21 & 39,81 \\
\hline \multicolumn{10}{|c|}{ Panel D : Book to Market (In Percentage) } \\
\hline Small & 7,67 & 16,92 & 26,44 & 24,21 & 15,80 & 11,01 & 23,21 & 16,43 & 11,37 \\
\hline Big & 24,03 & 15,85 & 9,09 & 9,71 & 17,18 & 22,08 & 10,53 & 16,84 & 21,61 \\
\hline \multicolumn{10}{|c|}{ Panel E : Profitability (In Percentage) } \\
\hline Small & 8,00 & 16,73 & 24,92 & 22,96 & 15,55 & 11,14 & 22,21 & 16,13 & 11,30 \\
\hline Big & 25,57 & 16,05 & 8,73 & 9,73 & 17,45 & 23,16 & 10,82 & 17,11 & 22,42 \\
\hline \multicolumn{10}{|c|}{ Panel F : Investments (In Percentage) } \\
\hline Small & 5,92 & 11,31 & 15,80 & 15,85 & 9,43 & 7,74 & 9,61 & 10,20 & 13,23 \\
\hline Big & 48,00 & 12,42 & 6,54 & 11,34 & 13,58 & 42,05 & 4,69 & 10,79 & 51,48 \\
\hline
\end{tabular}

\section{Empirical Result in Thailand}

We used the same method as Indonesia for testing the best model in Thailand. Based on the comparison of information criteria values in Table 6 , it is found that the TARCH model is the most optimal time varying beta model in Thailand with the smallest AIC, SIC, HIC values compared to other models. However, the information value of the TARCH criterion is slightly different from GARCH $(1,1)$ so that the second most optimal model is GARCH $(1,1)$. The TARCH model also yields a significant beta at the 1 percent level. Beta values, both static and dynamic in the Thai market, are negative for all portfolios, except for B / M OP which uses the Kalman Filter method. The static beta value is in the range of $-0,715$ in the $\mathrm{S} / \mathrm{L}$ BM portfolio to $-0,325$ in the B / L BM portfolio. With the TARCH model, the resulting beta value is in the range of $-0,717$ in the $\mathrm{S} / \mathrm{L}$ BM portfolio to $-0,315$ in the INV B / H portfolio. A negative value indicates that the portfolio stock price movement is against the market. This means that returns on stocks and markets have a negative relationship. Thus, if the market share yield increases, the portfolio return will decrease. Stocks with a negative beta usually attract investors when the market is bearish because the stock yields move in the opposite direction (increase). 
Table 6. The Comparison of Time-Varying Beta and Information Criteria - Thailand

\begin{tabular}{|c|c|c|c|c|c|c|c|c|c|c|c|c|c|c|c|}
\hline Portfolio & \multicolumn{2}{|c|}{$\beta^{L S}$} & \multirow{2}{*}{$\begin{array}{c}A I C \\
-7,509\end{array}$} & \multirow{2}{*}{$\frac{S I C}{-7,494}$} & \multirow{2}{*}{$\begin{array}{c}H I C \\
-7,504\end{array}$} & \multicolumn{2}{|l|}{$\beta^{G}$} & \multirow{2}{*}{$\begin{array}{c}A I C \\
-7,532\end{array}$} & \multirow{2}{*}{$\frac{S I C}{-7,509}$} & \multirow{2}{*}{$\begin{array}{c}H I C \\
-7,523\end{array}$} & \multicolumn{2}{|c|}{$\beta^{E G}$} & \multirow{2}{*}{$\begin{array}{c}A I C \\
-7,530\end{array}$} & \multirow{2}{*}{$\frac{S I C}{-7,505}$} & \multirow{2}{*}{$\begin{array}{c}H I C \\
-7,521\end{array}$} \\
\hline $\mathrm{S} / \mathrm{L} \mathrm{BM}$ & $-0,715$ & $* * *$ & & & & $-0,717$ & $* * *$ & & & & $-0,719$ & $* * *$ & & & \\
\hline S/M BM & $-0,481$ & $* * *$ & $-8,303$ & $-8,288$ & $-8,297$ & $-0,485$ & $* * *$ & $-8,324$ & $-8,302$ & $-8,316$ & $-0,484$ & $* * *$ & $-8,323$ & $-8,299$ & $-8,314$ \\
\hline S/H BM & $-0,423$ & $* * *$ & $-8,786$ & $-8,771$ & $-8,781$ & $-0,422$ & $* * *$ & $-8,823$ & $-8,801$ & $-8,815$ & $-0,423$ & $* * *$ & $-8,819$ & $-8,794$ & $-8,810$ \\
\hline B/L BM & $-0,325$ & $* * *$ & $-8,914$ & $-8,899$ & $-8,908$ & $-0,318$ & $* * *$ & $-8,996$ & $-8,974$ & $-8,988$ & $-0,319$ & $* * *$ & $-8,997$ & $-8,972$ & $-8,988$ \\
\hline $\begin{array}{l}\mathrm{B} / \mathrm{M} \\
\mathrm{BM}\end{array}$ & $-0,594$ & $* * *$ & $-8,500$ & $-8,485$ & $-8,495$ & $-0,603$ & $* * *$ & $-8,532$ & $-8,510$ & $-8,524$ & $-0,604$ & $* * *$ & $-8,530$ & $-8,506$ & $-8,521$ \\
\hline B/H BM & $-0,618$ & $* * *$ & $-7,832$ & $-7,817$ & $-7,827$ & $-0,622$ & $* * *$ & $-7,855$ & $-7,833$ & $-7,847$ & $-0,621$ & $* * *$ & $-7,856$ & $-7,832$ & $-7,847$ \\
\hline S/L OP & $-0,461$ & $* * *$ & $-8,577$ & $-8,562$ & $-8,572$ & $-0,461$ & $* * *$ & $-8,623$ & $-8,001$ & $-8,615$ & $-0,459$ & $* * *$ & $-8,627$ & $-8,600$ & $-8,618$ \\
\hline S/M OP & $-0,434$ & $* * *$ & $-8,305$ & $-8,290$ & $-8,299$ & $-0,436$ & $* * *$ & $-8,330$ & $-8,308$ & $-8,322$ & $-0,435$ & *** & $-8,328$ & $-8,303$ & $-8,319$ \\
\hline S/H OP & $-0,430$ & $* * *$ & $-8,318$ & $-8,304$ & $-8,313$ & $-0,434$ & $* * *$ & $-8,345$ & $-8,323$ & $-8,337$ & $-0,431$ & $* * *$ & $-8,344$ & $-8,320$ & $-8,335$ \\
\hline $\mathrm{B} / \mathrm{L} \mathrm{OP}$ & $-0,347$ & $* * *$ & $-8,691$ & $-8,676$ & $-8,686$ & $-0,340$ & $* * *$ & $-8,728$ & $-8,706$ & $-8,720$ & $-0,337$ & $* * *$ & $-8,725$ & $-8,700$ & $-8,716$ \\
\hline B/M OP & $-0,617$ & $* * *$ & $-8,296$ & $-8,282$ & $-8,291$ & $-0,649$ & $* * *$ & $-8,343$ & $-8,321$ & $-8,335$ & $-0,652$ & $* * *$ & $-8,341$ & $-8,316$ & $-8,332$ \\
\hline B/H OP & $-0,378$ & $* * *$ & $-8,861$ & $-8,846$ & $-8,855$ & $-0,369$ & $* * *$ & $-8,928$ & $-8,906$ & $-8,920$ & $-0,371$ & $* * *$ & $-8,924$ & $-8,900$ & $-8,915$ \\
\hline S/L INV & $-0,411$ & $* * *$ & $-8,624$ & $-8,609$ & $-8,619$ & $-0,410$ & $* * *$ & $-8,648$ & $-8,626$ & $-8,640$ & $-0,410$ & $* * *$ & $-8,644$ & $-8,619$ & $-8,635$ \\
\hline $\begin{array}{l}\text { S/M } \\
\text { INV }\end{array}$ & $-0,401$ & $* * *$ & $-8,339$ & $-8,325$ & $-8,334$ & $-0,405$ & $* * *$ & $-8,351$ & $-8,332$ & $-8,346$ & $-0,405$ & $* * *$ & $-8,353$ & $-8,329$ & $-8,344$ \\
\hline S/H INV & $-0,624$ & $* * *$ & $-8,217$ & $-8,202$ & $-8,211$ & $-0,627$ & $* * *$ & $-8,243$ & $-8,221$ & $-8,235$ & $-0,624$ & $* * *$ & $-8,240$ & $-8,215$ & $-8,231$ \\
\hline B/L INV & $-0,540$ & $* * *$ & $-8,282$ & $-8,267$ & $-8,276$ & $-0,551$ & $* * *$ & $-8,304$ & $-8,282$ & $-8,296$ & $-0,552$ & $* * *$ & $-8,302$ & $-8,277$ & $-8,293$ \\
\hline $\begin{array}{l}\mathrm{B} / \mathrm{M} \\
\mathrm{INV}\end{array}$ & $-0,635$ & $* * *$ & $-8,450$ & $-8,435$ & $-8,445$ & $-0,634$ & $* * *$ & $-8,505$ & $-8,483$ & $-8,497$ & $-0,636$ & $* * *$ & $-8,500$ & $-8,476$ & $-8,491$ \\
\hline $\begin{array}{l}\text { B/H } \\
\text { INV }\end{array}$ & $-0,328$ & $* * *$ & $-8,818$ & $-8,803$ & $-8,812$ & $-0,316$ & $* * *$ & $-8,887$ & $-8,865$ & $-8,879$ & $-0,315$ & $* * *$ & $-8,882$ & $-8,857$ & $-8,873$ \\
\hline
\end{tabular}

\begin{tabular}{|c|c|c|c|c|c|c|c|c|c|c|c|c|c|}
\hline Portfolio & $\beta^{T A}$ & & $A I C$ & $S I C$ & $H I C$ & $\beta^{K R C}$ & $A I C$ & $S I C$ & $H I C$ & $\beta^{K A R}$ & $A I C$ & $S I C$ & $H I C$ \\
\hline S/L BM & $-0,717$ & $* * *$ & $-7,532$ & $-7,507$ & $-7,523$ & $-3,134$ & $-7,440$ & $-1,162$ & $-1,166$ & $-3,263$ & $-1,169$ & $-1,159$ & $-1,165$ \\
\hline $4 \mathrm{BM}$ & $-0,485$ & $* * *$ & 327 & $-8,302$ & $-8,318$ & $-0,572$ & $-8,231$ & $-3,604$ & $-3,609$ & $-0,635$ & $-3,611$ & $-3,601$ & $-3,608$ \\
\hline S/H BM & $-0,422$ & $* * *$ & ,824 & $-8,799$ & $-8,815$ & $-1,339$ & $-8,713$ & $-3,404$ & $-3,408$ & $-1,396$ & $-3,411$ & $-3,401$ & $-3,407$ \\
\hline $\mathrm{B} / \mathrm{L} \mathrm{BM}$ & $-0,317$ & $* * *$ & $-9,001$ & $-8,976$ & $-8,992$ & $-0,454$ & $-8,840$ & $-3,908$ & $-3,913$ & $-0,468$ & $-3,915$ & $-3,905$ & $-3,911$ \\
\hline $\mathrm{B} / \mathrm{M} \mathrm{BM}$ & $-0,603$ & $* * *$ & $-8,533$ & $-8,509$ & $-8,524$ & $-1,548$ & $-8,428$ & $-3,489$ & $-3,494$ & $-1,588$ & $-3,496$ & $-3,486$ & $-3,492$ \\
\hline $\mathrm{B} / \mathrm{H} \mathrm{BM}$ & $-0,622$ & $* * *$ & $-7,854$ & $-7,830$ & $-7,845$ & $-2,250$ & $-7,762$ & $-1,524$ & $-1,529$ & $-2,368$ & $-1,531$ & $-1,521$ & $-1,527$ \\
\hline $\mathrm{S} / \mathrm{L}$ & $-0,460$ & $* * *$ & $-8,634$ & $-8,609$ & $-8,625$ & $-1,142$ & $-8,505$ & $-3,961$ & $-3,965$ & $-1,144$ & $-3,967$ & $-3,957$ & $-3,963$ \\
\hline $\mathrm{S} / \mathrm{M}$ & $-0,435$ & $* * *$ & $-8,331$ & $-8,306$ & $-8,322$ & $-0,997$ & $-8,233$ & $-2,106$ & $-2,110$ & $-1,048$ & $-2,112$ & $-2,103$ & $-2,109$ \\
\hline S/H OP & $-0,435$ & $* * *$ & $-8,347$ & $-8,322$ & $-8,338$ & $-0,735$ & $-8,247$ & $-3,506$ & $-3,510$ & $-0,743$ & $-3,512$ & $-3,503$ & $-3,509$ \\
\hline B/L OP & $-0,339$ & $* * *$ & $-8,728$ & $-8,704$ & $-8,719$ & $-1,484$ & $-8,618$ & $-3,121$ & $-3,126$ & $-1,505$ & $-3,128$ & $-3,118$ & $-3,124$ \\
\hline B/M OP & $-0,651$ & $* * *$ & $-8,344$ & $-8,319$ & $-8,335$ & 0,439 & $-8,225$ & $-3,269$ & $-3,274$ & 0,426 & $-3,276$ & $-3,267$ & $-3,273$ \\
\hline B/H OP & $-0,368$ & $* * *$ & $-8,932$ & $-8,908$ & $-8,923$ & $-1,890$ & $-8,788$ & $-2,604$ & $-2,608$ & $-1,982$ & $-2,611$ & $-2,601$ & $-2,607$ \\
\hline S/L INV & $-0,409$ & $* * *$ & $-8,649$ & $-8,625$ & $-8,640$ & $-0,118$ & $-8,552$ & $-3,796$ & $-3,801$ & $-0,220$ & $-3,804$ & $-3,794$ & $-3,800$ \\
\hline S/M INV & $-0,404$ & $* * *$ & $-8,357$ & $-8,333$ & $-8,348$ & $-1,868$ & $-8,268$ & $-2,392$ & $-2,397$ & $-1,944$ & $-2,399$ & $-2,389$ & $-2,395$ \\
\hline S/H INV & $-0,627$ & $* * *$ & $-8,244$ & $-8,219$ & $-8,235$ & $-1,028$ & $-8,145$ & $-3,412$ & $-3,416$ & $-1,033$ & $-3,418$ & $-3,408$ & $-3,415$ \\
\hline B/L INV & $-0,552$ & $* * *$ & $-8,304$ & $-8,279$ & $-8,295$ & $-1,514$ & $-8,210$ & $-2,843$ & $-2,847$ & $-1,569$ & $-2,849$ & $-2,840$ & $-2,846$ \\
\hline B/M INV & $-0,633$ & $* * *$ & & $-8,480$ & $-8,495$ & $-1,627$ & $-8,378$ & $-2,730$ & $-2,734$ & $-1,665$ & $-2,736$ & $-2,726$ & $-2,733$ \\
\hline B/H INV & $-0,315$ & $* * *$ & $-8,891$ & $-8,866$ & $-8,882$ & $-0,604$ & $-8,745$ & $-4,263$ & $-4,268$ & $-0,634$ & $-4,270$ & $-4,260$ & $-4,266$ \\
\hline
\end{tabular}

\begin{tabular}{|c|c|c|c|c|c|c|c|c|c|}
\hline Portfolio & $\beta^{K R W}$ & $A I C$ & SIC & $H I C$ & $S S$ & & $A I C$ & $S I C$ & $H I C$ \\
\hline S/L BM & $-9,034$ & $-0,497$ & $-0,492$ & $-0,495$ & $-0,16 \times 10^{-5}$ & & $-7,509$ & $-7,492$ & $-7,503$ \\
\hline S/M BM & $-4,508$ & $-2,891$ & $-2,886$ & $-2,889$ & $-0,55 \times 10^{-5}$ & $* * *$ & $-8,319$ & $-8,302$ & $-8,313$ \\
\hline S/H BM & $-4,416$ & $-2,736$ & $-2,731$ & $-2,734$ & $-0,42 \times 10^{-5}$ & $* * *$ & $-8,802$ & $-8,785$ & $-8,796$ \\
\hline $\mathrm{B} / \mathrm{L} \mathrm{BM}$ & $-3,789$ & $-3,180$ & $-3,175$ & $-3,178$ & $-0,60 \times 10^{-5}$ & $* * *$ & $-8,951$ & $-8,934$ & $-8,945$ \\
\hline B/M BM & $-4,246$ & $-2,650$ & $-2,645$ & $-2,648$ & $-0,27 \times 10^{-5}$ & $* * *$ & $-8,504$ & $-8,487$ & $-8,498$ \\
\hline B/H BM & $-8,407$ & $-0,844$ & $-0,840$ & $-0,843$ & $-0,33 \times 10^{-5}$ & $* * *$ & $-7,835$ & $-7,818$ & $-7,829$ \\
\hline $\mathrm{S} / \mathrm{L} \mathrm{OP}$ & $-4,894$ & $-3,273$ & $-3,268$ & $-3,271$ & $-0,40 \times 10^{-5}$ & $* * *$ & $-8,589$ & $-8,571$ & $-8,582$ \\
\hline S/M OP & $-4,821$ & $-1,426$ & $-1,421$ & $-1,424$ & $-0,57 \times 10^{-5}$ & $* * *$ & $-8,322$ & $-8,305$ & $-8,316$ \\
\hline S/H OP & $-2,307$ & $-2,824$ & $-2,819$ & $-2,822$ & $-0,46 \times 10^{-5}$ & $* * *$ & $-8,330$ & $-8,313$ & $-8,324$ \\
\hline $\mathrm{B} / \mathrm{L} \mathrm{OP}$ & $-4,922$ & $-2,437$ & $-2,432$ & $-2,435$ & $-0,43 \times 10^{-5}$ & $* * *$ & $-8,705$ & $-8,688$ & $-8,699$ \\
\hline $\mathrm{B} / \mathrm{M} \mathrm{OP}$ & $-0,386$ & $-2,609$ & $-2,604$ & $-2,608$ & $-0,61 \times 10^{-5}$ & $* * *$ & $-8,317$ & $-8,300$ & $-8,311$ \\
\hline B/H OP & $-7,508$ & $-1,930$ & $-1,925$ & $-1,928$ & $-0,37 \times 10^{-5}$ & $* * *$ & $-8,874$ & $-8,856$ & $-8,867$ \\
\hline S/L INV & $-3,436$ & $-3,130$ & $-3,125$ & $-3,128$ & $-0,42 \times 10^{-5}$ & $* * *$ & $-8,637$ & $-8,620$ & $-8,630$ \\
\hline S/M INV & $-5,827$ & $-1,720$ & $-1,715$ & $-1,718$ & $-0,59 \times 10^{-5}$ & $* * *$ & $-8,360$ & $-8,342$ & $-8,353$ \\
\hline S/H INV & $-3,355$ & $-2,600$ & $-2,595$ & $-2,598$ & $-0,33 \times 10^{-5}$ & $* * *$ & $-8,222$ & $-8,204$ & $-8,215$ \\
\hline B/L INV & $-4,206$ & $-2,176$ & $-2,171$ & $-2,175$ & $-0,55 \times 10^{-5}$ & $* * *$ & $-8,298$ & $-8,281$ & $-8,292$ \\
\hline B/M INV & $-4,846$ & $-2,054$ & $-2,049$ & $-2,052$ & $-0,12 \times 10^{-5}$ & & $-8,450$ & $-8,433$ & $-8,444$ \\
\hline B/H INV & $-4,287$ & $-3,417$ & $-3,412$ & $-3,415$ & $-0,63 \times 10^{-5}$ & $* * *$ & $-8,855$ & $-8,838$ & $-8,849$ \\
\hline
\end{tabular}

Note: $* * *$ indicates a confidence level at 1 percent, $* *$ indicates a confidence level at 5 percent, and $*$ indicates a confidence level at 10 percent. 
Based on the explanation of the analysis results previously described, it is known that the most optimal model in testing time varying beta in Indonesia and Thailand by using the Fama French five-factor asset pricing model and using information criteria as a criterion in choosing the optimal model is the GARCH model $(1,1)$ and TARCH. The results of this study are reminiscent of Occam's razor principle or known as the law of parsimony which states that simpler solutions (models) tend to be more correct than complex ones. In Marsh and Hau (1996) and Marsh and Hau (1998) it is also stated that the value of parsimony in structural equation modeling (all other things being equal), a simpler and more parsimony model with less parameter estimates used is better than the model. more complex.

Regarding the test results in Indonesia with GARCH $(1,1)$ being the most optimal model, Lim and Sek (2013) also found that the GARCH symmetric model performed better than the GARCH asymmetric model in the normal period of the Malaysian capital market. Meanwhile, regarding the test results in Thailand with TARCH being the most optimal model, Gabriel (2012) also found that TARCH is the most successful model in predicting volatility in the Romanian market index.

The Kalman Filter, which was initially thought to be the most optimal model based on literature review in several developed and developing countries, turned out to have the lowest optimization power compared to other models in keeping information from being lost by the given model. This at the same time rejects the research hypothesis for the two countries. Piche (2016) mentions one of the weaknesses of the Kalman Filter, namely if the measurement parameters of noise covariance in the Kalman Filter are relatively small to the noise, the measurement weight relative to the process model becomes too much and the state estimation becomes erratic. On the other hand, if the parameters are too large, the filter gives too little weight to the measurement and the response is sluggish. Noise in this case determines the accuracy and time lag in the estimated value. Because the Kalman Filter estimates the unobserved variable, the role of the parameter and its relation to the noise contained therein greatly determines the accuracy of the estimate.

\section{CONCLUSION}

This study aims to study a model in building a systematic risk that varies with time varying beta using the Fama-French five-factor asset pricing model, to find out how the market risk premium affects the portfolio returns of the five Fama-French asset pricing factors in each country by using various models, and to find out which model is the most optimal according to the characteristics of Indonesia and Thailand based on information criteria.

From the research results it can be concluded that the following are:

1. The GARCH model $(1,1)$ is the most optimal model in estimating the time varying beta in Indonesia and the TARCH model in Thailand. This is in contrast to the research of Choudhry and $\mathrm{Wu}(2008)$ which stated that the Kalman Filter outperformed the GARCH model.

2. The Kalman Filter model has the lowest optimization power compared to other models because it has the lowest AIC, SIC, and HIC values in both countries. The findings of this study reject the hypothesis built on the results of previous studies. However, most of these studies are conducted in developing markets, whereas this study examines developed market countries.

3. Akaike Information Criterion, like many other quality measurement models, considers two things, namely the goodness of fit and the simplicity of the model. If the measurement of the model only considers the quality based on the goodness of fit, it will cause many overfitted models to occur. On the other hand, if the measurement of the model only considers its simplicity, then there will be underfitted models in determining the optimal model. In relation to this study, the most optimal model belongs to GARCH $(1,1)$ and TARCH which are still classified as simple models. The TARCH model is an extension of the GARCH model by adding a dummy variable to the existence of the leverage effect. 
4. The results issued on the Kalman Filter modeling for Indonesia and Thailand in this modeling are insignificant. This is not surprising given the reference to Coutts et al. (1997) in carrying out the constancy test for the random walk specification (in this case the Kalman Filter) parameter found that the null hypothesis of parameter stability was rejected at the five percent level in each industry in the sample.

\section{REFERENCES}

Bollerslev, T. (1986). Generalized autoregressive conditional heteroskedasticity. Journal of Econometrics, 31, 307-327.

Brooks, C. (2014). Introductory econometrics for finance. Cambridge: Cambridge University Press.

Brooks, R. D., Faff, R. W., \& McKenzie, M. D. (1998). Time-varying beta risk of Australian industry portfolios: A comparison of modelling techniques. Australian Journal of Management, 23(1), 1-22.

Campbell, J. Y. \& Vuolteenaho, T. (2004). Bad beta, good beta. The American Economic Review, 94(5), 1249-1275.

Coutts, J. A., Roberts, J., \& Mills, T. C. (1997). Parameter stability in the market model: Tests and time varying parameter estimation with uk data. The Statistician, 46(1), 141-163.

Faff, R. W., Hillier, D., \& Hillier, J. (2000). Time varying beta risk: An analysis of alternative modelling techniques. Journal of Business Finance \& Accounting, 27(5-6), 523-554.

Fama, E. F., \& French, K. R. (1992). The cross-section of expected stock returns. The Journal of Finance, 47(2), 427-465.

Fama, E. F., \& French, K. R. (1993). Common risk factors in the returns on stocks and bonds. Journal of Financial Economics, 33(1), 32-56.

Fama, E. F., \& French, K. R. (1997). Industry costs of equity. Journal of Financial Economics, 43(2), 153-193.

Fama, E. F., \& French, K. R. (2015). A five-factor asset pricing model. Journal of Financial Economics, 116(1), 1-22.

Ferson, W. E., \& Harvey, C. R. (1999). Conditioning variables and the cross section of stock returns. The Journal of Finance, 54(4), 1325-1360.

Gabriel, A. S. (2012). Evaluating the forecasting performance of GARCH models, evidence from romania. Procedia - Social and Behavioral Sciences, 62, 1006-1010.

Glosten, L. R., Jagannathan, R., \& Runkle, D. E. (1993). On the relation between the expected value and the volatility of the nominal excess return on stocks. The Journal of Finance, 48(5), 1779-1801.

International Monetary Fund. (2019). World economic outlook, October 2019: Global manufacturing downturn, rising trade barriers. Washington, D.C: International Monetary Fund.

Jagannathan, R., \& Wang, Z. (1996). The conditional CAPM and the cross-section of expected returns. The Journal of Finance, 51(1), 3-53.

Lim, C. M., \& Sek, S. K. (2013). Comparing the performances of GARCH-type models in capturing the stock market volatility in malaysia. Procedia Economics and Finance, 5, 478487.

Marsh, H., \& Hau, K. T. (1996). Assessing goodness of fit: Is parsimony always desirable? The Journal of Experimental Education, 64(4), 364-390.

Marsh, H., \& Hau, K.-T. (1998). Is parsimony always desirable: Response to sivo and willson, hoyle, markus, mulaik, tweedledee, tweedledum, the cheshire cat, and others. The Journal of Experimental Education, 66(3), 274-285.

Jurnal Manajemen dan Organisasi

(JMO), 11 No.

Vol. 11 No. 3, Hal. 189-202

Nelson, D. B. (1991). Conditional heteroskedasticity in asset returns: A new approach. Econometrica, 59(2), 347-370. 
Nieto, B., Orbe, S., \& Zarraga, A. (2014). Time-varying market beta: Does the estimation methodology matter? SORT-Statistics and Operations Research Transactions, 38(1), 13 42.

Piche, R. (2016). Online tests of kalman filter consistency. International Journal of Adaptive Control and Signal Processing, 30(1), 115-124.

Petkova, R., \& Zhang, L. (2005). Is value riskier than growth? Journal of Financial Economics, 78(1), 187-202.

Schaefer, S., Brealey, R., Hodges, S., \& Thomas, H. (1975). Alternative models of systematic risk. In: E. Elton \& M. Gruber (Eds), International capital markets: An inter- and intracountry analysis (pp. 150-161). Amsterdam: North-Holland.

Schwert, G. W., \& Seguin, P. J. (1990). Heteroskedasticity in stock returns. The Journal of Finance, 45(4), 1129-1155.

Sharpe, W. F. (1970). Efficient capital markets: A review of theory and empirical work: Discussion. The Journal of Finance, 25(2), 418-420.

Wells, C. (1996). The kalman filter in finance (advanced studies in theoretical and applied econometrics), Volume 32. Berlin: Springer Science Business Media, B.V. 